\title{
İnönü Muharebeleri Esnasında İki Din Adamı: Müftü Mehmet Nuri (Kırıkkanat) ve Müftü Mustafa (Kileci) Efendiler ${ }^{1}$
}

\author{
Esra SARIKOYUNCU DEĞERLi² - Ali SARIKOYUNCU ${ }^{3}$
}

\section{Öz}

Millî Mücadele'de pek çok din adamı gibi, Bilecik Müftüsü Mehmet Nuri (Kırıkkanat) ile Söğüt Müftüsü Mustafa Lütfi (Kileci) Efendiler de görev almışlardır. Mücadele fikrinin doğuşunda ve Kuva-yı Milliye’nin kuruluş ve faaliyetlerinde adı geçenlerin üstün hizmetleri olmuştur. Ayrıca Mehmet Nuri ve Mustafa Lütfi Efendilerin Türk milletinin makûs talihini yendiği "İnönü Muharebeleri" esnasında da çok önemli katkıları olmuştur. Çalışmamızda arşiv belgelerinden de yararlanarak, onların söz konusu hizmetlerinden söz edilmiştir.

Anahtar Kelimeler: Millî Mücadele, İnönü Muharebeleri, Bilecik Müftüsü Mehmet Nuri (Kırıkkanat), Söğüt Müftüsü Mustafa Lütfi (Kileci)

Atıf: Sarıkoyuncu Değerli, E. ve Sarıkoyuncu, A. (2021). İnönü muharebeleri esnasında iki din adamı: Müftü Mehmet Nuri (Kırıkkanat) ve Müftü Mustafa (Kileci) Efendiler. Anadolu Üniversitesi Sosyal Bilimler Dergisi, 21(Özel Sayı), 87100 .

\footnotetext{
${ }^{1}$ Bu çalıșma etik kurul izin belgesi gerektirmemektedir.

${ }^{2}$ Kütahya Dumlupınar Üniversitesi Fen-Edebiyat Fakültesi Tarih Bölümü, esra.sdegerli@dpu.edu.tr, ORCID: 0000-0003-3372-1034

${ }^{3}$ Kütahya Dumlupınar Üniversitesi Fen-Edebiyat Fakültesi Tarih Bölümü, ali.sarıkoyuncu@dpu.edu.tr, ORCID: 0000-0003-4646-0056
} 


\title{
Two Religious Men During the Battles of İnönü: Müftü Mehmet Nuri (Kırıkkanat) and Müftü Mustafa (Kileci) Efendi
}

\author{
Esra SARIKOYUNCU DEĞERLİ ${ }^{4}$ - Ali SARIKOYUNCU ${ }^{5}$
}

\begin{abstract}
Like many clergymen, Bilecik Mufti Mehmet Nuri Efendi (Kırıkkanat) and Söğ̈̈t Mufti Mustafa Lütfi (Kileci) Efendi also took part in the War of Independence. Those who were mentioned at the stage of the idea formation of struggle and in the establishment and activities of the Kuva-yi Milliye had superior services. In addition, Mehmet Nuri Efendi and Mustafa Lütfi Efendi made a lot of contributions during the "Battle of İnönü", during which the misfortune of the Turkish nation has also been defeated. In our study, by making use of archive documents, their services were mentioned.
\end{abstract}

Keywords: National Struggle, Battles of İnönü, Bilecik Mufti Mehmet Nuri (Kırıkkanat), Söğüt Mufti Mustafa Lütfi (Kileci)

\footnotetext{
${ }^{4}$ Kütahya Dumlupınar University Faculty of Arts Sciences Department of History, esra.sdegerli@dpu.edu.tr, ORCID: 0000-0003-3372-1034

${ }^{5}$ Kütahya Dumlupınar University Faculty of Arts Sciences Department of History, ali.sarıkoyuncu@dpu.edu.tr, ORCID: 0000-0003-4646-0056
} 


\section{Giriş}

1364-1830 yılları arasında, yaklaşık 500 yıl Türk yönetiminde bulunan Yunanistan, Rusya ve Osmanlı arasında imzalanan 14 Eylül 1829 tarihli Edirne antlaşması sonrasında, 1830 yılında bağımsızlığını elde etmiştir. Bu tarihle birlikte Rumların Anadolu'ya yönelik istekleri de su yüzüne çıkmıştır. Esasen bağımsızlık için 1821'de Mora'da girişilen isyan ile birlikte büyük mefkure, büyük fikir olarak da adlandırılan "Megali İdea", Yunanlıların temel politikası haline gelmiştir. Başka bir ifadeyle; bu politika ile, hem Asya'da hem de Avrupa toprak sahibi olan büyük Yunanistan hayalini gerçekleştirmek amacıyla harekete geçmişlerdir.

Böylece Yunanistan'ın sınırları Anadolu ortalarını içine alan, Akdeniz, Adriyatik ve Karpat Dağları ile Tuna nehrine kadar uzanan büyük bir devlete sahip olacaktı. Bu devletin başkenti de İstanbul olacaktı (Akçura, 1940, s. 19; İnan, 1986, s. 93).

Aynı zamanda Hellen emperyalizmi olarak da zikredilen Megali İdea'nın gerçekleştirilmesi de iki aşamada şöyle olacaktı (Şahin,1990, s. 11):

1- Öncelikle bağımsız Yunanistan'ın; İyonya Adaları (Yedi Ada)'nı, Teselya ve Epir ile birlikte Girit, Oniki Ada ve Kıbrıs'ı Anadolu'nun Sakarya'ya kadar olan topraklarını İstanbul dahil olmak üzere sahip çımak.

2- Sonra da Karadeniz sahillerini ele geçirerek, Pontus Devletini yeniden hayata geçirmek.

$\mathrm{Bu}$ hususların gerçekleşmesiyle, Yunan başkanlarından Elefteries Venizelos'un; "Yunanistan'in dört denizle yıkanan ve kendi penceresinden Karadeniz’i de seyreden bir ülke olacă̆ı” şeklindeki rüyası da gerçekleşmiş olacaktı (İnan, 1986, s. 95).

Megali İdea'nın ilk ciddi adımını 1821'de Mora isyanı çıkaran Patros Rum Piskoposu Germanos atmıştı. Bu arada Yunanistan'ın bağımsızlık hareketleri Fener-Rum Patrikhanesi tarafından yönetilmiştir. Bu konuda Patrik V. Gregorius başrolü oynamıştır. Adı geçen ihanetinin cezasını, Patrikhanenin kapalı kapısının önünde ipe çekilmekle çekmiştir (Ercan, 1986, s. 195-209).

Yukarıda da belirtildiği üzere, 1830 yılında bağımsız bir devlet olan Yunanistan, daha sonraki günler ve yıllarda da Megali İdea konusunda başarılı adımlar atmıştır. Şöyle ki; 1864'de Yedi Ada'yı elde eden Yunanistan, 93 Harbi olarak da bilinen 1877-1878 tarihleri arasında gerçekleşen Osmanlı-Rus Savaşı esnasında Rusların yanında yer almış, yardımlarda bulunmuştu. Bu yardımlar Rusya tarafından takdir edilmiş ve Teselya Sancağı Yunanistan'a verilmişti. 1911-1913 yılları arasında cereyan eden Balkan Savaşları ile de İşkodra, Selanik, Kavala, Serez, Yanya, Manastır, Limni, Midilli ve Sakız adalarını da alarak Yunanistan sinırlarını bir hayli genişletti. Eylül 1913 tarihine gelindiğinde ise Yunanistan Girit Adası’nın yönetimini elde etti.

Megali idea'nın kalan hedeflerini gerçekleştirme hususunda Birinci Dünya Savaşı özellikle Başbakan Venizelos tarafından büyük bir fırsat olarak değerlendirilmiştir. Onun izlediği etkin siyaset neticesinde, 11 Haziran 1917 tarihinde Yunanistan'ı İtilaf güçleri yanında Birinci Dünya Savaşı'na girdi. Bu sayede savaş sonrasında Anadolu'da hayal ettikleri topraklara kavuşabileceklerdi. Nitekim 30 Ekim 1918'de Osmanlı Devleti'nin Mondros Ateşkesini imzalaması sonrası, İtilaf güçleri harekete geçerek, yer yer Türk topraklarını işgale koyuldular. Ayrıca emperyalistler kendi işgallerinin yanı sıra, 18 Ocak 1919 tarihinde gerçekleştirdikleri Paris Barış Konferansı'nda, başta İzmir olmak üzere, Balıkesir'e kadar Batı Anadolu'nun büyük bir kısmını Yunanlılara bırakmakta bir sakınca görmediler (Tansel, 1991, s. 155-162). 
$\mathrm{Bu}$ şekilde Megali İdea için önemli bir fırsat yakalayan Yunanistan harekete geçti. İzmir ve civarında İngiltere ve Fransa'nın başını çektiği İtilaf güçlerinin güvenliklerini tehdit eden hiçbir olay yaşanmamasına rağmen, Mondros Ateşkesinin 7. Maddesini gerekçe gösterilerek, Yunan askerlerince İzmir 15 Mayıs 1919 tarihinde işgal edildi (Kurat, 1973, s. 842-853).

Anadolu topraklarına ilk adımını atan Yunanistan, daha sonraki günlerde de kuruluşundan itibaren sahip olmak istediği Anadolu topraklarını elde etmek için harekete geçti. İtilaf güçlerinin desteğindeki Yunan askerleri kısa sürede Batı Anadolu’yu işgal etmeyi başardılar. İzmir'in yanı sıra, Aydın, Manisa, Uşak, Afyonkarahisar, Kütahya, Bilecik ve Bursa topraklarını birer birer işgal edildi (Kocaoğlu, 2008, s. 26-29). Ayrıca Yunan ordusu, Eskişehir üzerinden Ankara’ya ulaşmak, dolayısıyla Sevr’i kabul ettirmek üzere harekete geçti.

Öncelikle Bilecik ve Bozüyük'te bulunan Türk ordusunu etkisiz hale getirmek istediler. İki kuvvet İnönü ve çevresi topraklarında karşı karşıya geldi. 6-11 Ocak 1921- 23 Mart-1 Nisan 1921 tarihlerinde Türk ve Yunan güçleri arasında kanlı vuruşmalar oldu. Tarihimizde "I. ve II. İnönü Muharebeleri” olarak adlandırılan vuruşmalar Türk ordusunun zaferiyle sonuçlanmıştır.

İnönü Muharebeleri esnasında Bilecik Müftüsü Mehmet Nuri (Kırıkkanat) ile Söğüt Müftüsü Mustafa Lütfi (Kileci) Efendilerin de üstün hizmetleri olmuştur. Onların bu hizmetlerinden söz etmeden önce yaşam öyküleri hakkında bilgi sunalım.

\section{Hayatları}

\section{Mehmet Nuri (Kırıkkanat)}

Mehmet Nuri Efendi, 1885'te Bilecik-Gölpazarı ilçesi, Şahinler köyünde dünyaya geldi. Babası aynı köy halkından Mustafa Efendi'dir (Gölpazarı Nüfus İdaresinden alınan bilgi). Ancak adı geçenin öğrenimi hakkında bilgi edinemedik. Bu konuda Diyanet İşleri Başkanlığı arşivindeki 1923-1047 numaralı dosyada da bilgi bulunamamıştır. Buna karşın; İstanbul Müftülüğü Meşihat arşivinde (İMMEŞ Arş.) bulunan Müftüler Defteri, C. 2, s. 223'de, Mehmet Nuri Efendi'nin Bilecik Akmescit Müderrisi iken, 2 Mart 1912'de anılan yer müftüsü olduğu kaydedilmiştir.

Milli Mücadele'nin başlamasıyla, ulusal harekatın yanında yer alan Müftü Mehmet Nuri Efendi ayrıca Askeri Polis Teşkilatı Bilecik Şubesi’nde de görev almıştır (ATASE Arş., Kl: 687, D: 140, Fh:1-8).

Kurtuluş Savaşı esnasında cephe ve cephe gerisinde askeri ve genel istihbaratı sağlamak, özellikle İstanbul'dan Anadolu'ya geçen kişilerin içine düşman tarafından sokulan casus ve propagandacıların menfi faaliyetlerini önlemek amacıyla; Askeri Polis (A.P veya P) Teşkilatı, Tetkik Heyeti Amirliği, Emniyet-i Umumiye, Müfettişlikleri ve Askeri Sansür Müdüriyeti gibi kuruluşlar görev yapmıştır. Bu kuruluşlar içerisinde önemli hizmetler üstlenen Askeri Polis Teşkilatı, 18 Temmuz 1920'de bizzat Genelkurmay Başkanı Fevzi (Çakmak) Paşa'nın emriyle Garp Cephesi'ne bağlı olarak kurulmuştur. “Garp Cephesi Askeri Polis Teşkilatı” adıyla çalışmalarına başlayan bu kuruluşun merkezi de Eskişehir idi. Bilecik başta olmak üzere, Anadolu’nun çeşitli yerlerinde Askeri Polis Teşkilatı’nın şubeleri de oluşturulmuştur (Sarıkoyuncu, 1992, s. 13-14).

Ulusal harekatın Bilecik ve çevresinde benimsenmesindeki ve Kuva-yı Milliye'nin ikmalindeki üstün hizmetlerinden, Yunan işgal kuvvetleri yetkilileri öteden beri rahatsızlık duyuyorlardı. Başarısızlıklarını da onun yöredeki hizmetlerini yorumluyorlardı. Aşağıda daha geniş söz edileceği üzere, Müftü Efendi'nin Askeri 
Polis Teşkilatındaki hizmetini fırsat bilen düşman pusu kurdu. 7 Nisan 1921 günü görevi başında tarassudu sırasında da Millî Mücadele kahramanı şehit edildi.

Onun şehit edilişi, 8 Nisan 1921 tarihinde Garp Cephesi Komutanı Albay İsmet Bey (İnönü) tarafından telgrafla Ankara'ya bildirildi (Askeri Tarih Belgeleri Dergisi, Sayı: 93, Belge No:2399). Ayrıca Bilecik (Ertuğrul) Livası Mutasarrıfı Salih Bey tarafından 22 Nisan 1921 tarihinde TBMM Başkanlığına gönderdiği telgrafta; "Ertuğrul Livası Müdafaa-i Hukuk Cemiyeti Merkez Heyeti Başkanı Bilecik Müftüsü Mehmet Nuri Efendi'dir" denildikten sonra, onun da düşman tarafından şehit edildiği belirtilmiştir (Belgelerle Türk Tarihi Dergisi, Say1:36, No:12).

Mehmet Nuri Efendi'nin Yunan askerlerince şehit edilişi, başta yetkililer olmak üzere herkesi derinden etkilemiştir. Onun ölümü Bileciklileri çok kederlendirdiği için halk tarafından bugün dahi söylenen "Bilecik Türküsü” yakılmıştır. Bu türkünün ilk dörtlüğü şöyledir (Sarıkoyuncu, 1992, s.35-36):

"Bilecik’in uzun olur urganı

Nuri Hoca Bilecik'in kurbanı

Mehmet Nuri Bilecik'in kurbanı

Git oğlum git sakın dönme sen geri”

Adı geçenin kabri şehit edildiği Deresakarı köyündedir. Prof. Dr. Ali Sarıkoyuncu tarafından kaleme alınan mezar baş taşında;

“Allah yolunda öldürülenlere ölü demeyin. Bilakis onlar diridirler. Lakin siz anlayamazsınız” (Kur'an-1 Kerim 2/154).

Ayet mealinden sonra onun Bilecik ve çevresi halkını Millî Mücadele'ye davet ettiği konuşmasına yer verilmiştir.

Kitabenin son cümlesi; “7 Nisan 1921 günü Ĕ̆demek Tepesinde Yunanllar tarafından şehir edilen Müftümüze minnet ve şükran hislerimizle... Ruhuna Fatiha” ifadesiyle bitmektedir.

Adı geçen şehit edildiğinde 36 yaşındaydı, evli olup, Lütfi ve Suna adlarında iki çocuk babasıydı. Ailesi 'KIRIKKANAT" soyadını almıştır (Sarıkoyuncu, 1992, s. 35).

\section{Söğüt Müftüsü Mustafa Lütfi (Kileci) Efendi}

Mustafa Lütfi Efendi, Söğüt'te 1866’da doğdu. Babası Kilecizade İsmail Efendi’dir.

İlk ve orta öğrenimini Söğüt’te tamamladıktan sonra, Yükseköğrenim için İstanbul'a gitti. İstanbul'da Fatih Medresesi'nde öğrenim gördü. Ocak 1906'da Ünyeli Hacı Hafız İbrahim Efendi'den icazetnamesini (diplomasını) aldı (DİB Arş., D:1923-1212).

Mustafa Lütfi Efendi, Yükseköğrenimi sonrası memleketi Söğüt'e döndü ve Mahkeme-i Şer'iye kâtipliğine atandı. Adı geçen aynı görevle birlikte ayrıca Söğüt Eytam Müdürlüğü vazifesini de üstlendi. 15 Ağustos 1911 yılında da Söğüt Müftüsü oldu (DİB Arş., D:1923-1212).

Millî Mücadele'nin ilk günlerinde ulusal harekâta katılan Mustafa Lütfi Efendi, 26 Temmuz 1928'de vefat etmiştir. Kabri Söğüt’tedir. Ailesi “KİLECİ” soyadını almıştır. 
Adı geçen Millî Mücadele'deki hizmetlerinden dolayı “Kırmızı Şeritli İstiklal Madalyası” ile taltif edilmiştir (DİB Arş., D:1923-1212).

İstiklal Madalyaları kurdelelerine göre; Beyaz, Kırmızı, Yeşil ve Kırmızı- Yeşil olmak üzere dört çeşittir. Beyaz kurdele; Cephe gerisinde hizmet edenlere, Kırmızı kurdele; Cephede fiilen düşmanla çarpışanlara, Yeşil kurdele; 15 Mayıs 1919- 9 Eylül 1922 tarihleri arasında Milletvekili olarak TBMM’nde görev yapanlara, Kırmızı- Yeşil kurdele; TBMM'de üye olup aynı zamanda cephede çarpışmalarda bulunanlara verilmiştir.

\section{İnönü Muharebeleri Öncesi Hizmetleri}

\section{Millî Mücadele Fikrinin Doğuşundaki Hizmetler}

Milli Mücadele, Türk ulusunun vatan topraklarını ve bağımsızlığını korumak amacıyla, iç ve dış düşmanlara karşı maddi ve manevi bütün olanaklarını ortaya koyarak savaştığı ve sonunda da zafere ulaştığı bir dönemdir. Ancak ölüm kalım mücadelesinin verildiği bu dönemin ilk günlerinde halk, Mustafa Kemal Atatürk'ün de ifade ettiği gibi "Hakiki vaziyeti anlamamışlardı. Fikirlerde karışıklık vardı. Dimağlar adeta durgun bir haldeydi...". Yine O'nun ifadesiyle, pek çok din adamı göreve koştu. “Gerçeği halka açıkladılar... doğru yolu gösteren vaaz ve öğütlerden sonra herkes çalışmaya başladı.” (Atatürk'ün Söylev ve Demeçleri, 1989, s. 208).

Bu bağlamda başta Denizli Müftüsü Ahmet Hulusi, İzmir Müftüsü Rahmetullah, Amasya Müftüleri Hacı Tevfik ve Abdurrahman Kamil, Ankara Müftüsü Mehmet Rıfat Efendiler olmak üzere nice Müftü, Vaiz ve İmam-Hatip göreve koşmuştur. Bilecik ve çevresinde de halkın ulusal harekât lehinde bilinçlendirilmesi ve Kuva-yı Milliye'nin ikmali hususundaki vazifeyi de Müftü Mehmet Nuri ve Müftü Mustafa Lütfi Efendiler üstlenmişlerdir. Örneğin; Mehmet Nuri ve Mustafa Lütfi Efendiler, camilerde, çarşı ve pazarlarda konuşmalar yaptılar, vaazlar verdiler. Müftü Mehmet Nuri Efendi, bir konuşmasını Bilecik Orhan Gazi Camii'nde yapmıştır. Kılıç da kuşanarak yaptığı bu tarihi konuşmasında O, şöyle haykırıyordu (Sarıkoyuncu, 1993, s. 20):

Milletin haysiyeti, şerefi, hürriyeti ve istiklali gerçekten tehlikeye düşmüştür. Yunan gâvurundan kurtulmak için gerekirse Bilecik’in bütün fertlerinin ölmeyi göze alması lazımdır.

Müftünüz olarak diyorum ki, alçak Yunan'ın zulüm ve vahşetine katlanmaktansa seve seve ölelim. Şehit olalım. Cennete gidelim. Ama önce düşmanı ata yadigârı yurttan kovalım. Bir ve beraber olalım. Bir araya gelip teşkilat kuralım.

Gazamız mübarek olsun. Allah bizimle beraberdir.

Mehmet Nuri Efendi'nin bu konuşması, halkın ulusal harekât lehinde bilinçlenmesinde etkili olmuştur. Hemen onun başkanlığında; Feyzizade Hafız Arif, Fabrikatör Ali, Arif Beyzade Hacı Halit, Dedezade Ali, Harmancızade Hayri ve Macaroğullarından Ömer Bey ve Efendilerin katılımı ile Ertuğrul Livası (Bilecik) Müdafaa-i Hukuk Cemiyeti faaliyete geçirilmiştir (Belgelerle Türk Tarihi Dergisi, Sayı:36, Belge No:12).

Aynı şekilde Müftü Mustafa Lütfi Efendi de Söğüt ve çevresi halkının ulusal harekât lehinde bilinçlenmesi hususunda gayret gösteriyordu. Bir defasında Söğüt Ulu Camii kürsüsünden;

"Ey cemaat, ey Söğütlüler!

Siz herhalde kadınlarınızı, kızlarınızı Yunan gavuruna peşkeş çekmek istiyorsunuz” gibi sert ifadelerle halka uyarıda bulunmuştur. 
Ayrıca onun girişimleri sonunda; Abdullah Timurlenkoğlu, Hakim Cevdet Baybura, Müftü Mustafa Lütfi Kileci, Nuri Büyüktuğrul, Sabri İpek, Mehmet Madenoğlu, Ragıp İpek, Hazım Şahin ve Ali Osman Yazgan Beyler ve Efendilerin katılımı ile Söğüt Müdafaa-i Hukuk Cemiyeti kurulmuştur (Beğenç, 1952, s. 23). Ayrıca, Halil Işık ve Necip Soydan da anılan cemiyette görev almışlardır (ATASE Arş., Kl:950, D:2, Fh:74).

Görüldügü üzere her iki din adamı halkın ulusal harekât yanında yer alması konusunda rehberlik etmişler ve ülkenin içine düştüğü durumu açık bir dille korkusuzca anlatmışlardır.

Türkiye Cumhuriyeti’nin 3'üncü Cumhurbaşkanı Celal Bayar’ın da belirttiği gibi “Bu yapılan şeyler bugün basit imiş gibi telakki olunabilir. Fakat aslında çok önemlidir. Düşünmeli ki, hükümetin baskısı, mukavemet aleyhtarı olan muhaliflerin ve İngiliz dostluğu ve himayesi politikasını güden Hürriyet ve İtilaf Partisi’nin Propagandası yüzünden tek kişinin "Müdafaa" fikrini özel surette söylemesi dahi bir mesele iken camilerde, meydanlarda böyle aleni surette silaha sarılmaktan başka çare kalmamıştır demenin de değeri büyüktü. Söyleyenler için fedakârlıktı (Bayar, 1982, s. 5 95).”

Millî Mücadele'nin ilk günlerinde Kuva-yı Milliye taraftarı olmak, halka önderlik etmek gerçekten bir fedakârlıktı. Sadrazam Damat Ferit, Haziran 1919'da Valilik ve Mutasarrıflıklara gönderdiği genelgede ulusal örgütlenmenin yasaklandığını, bu emre uymayanların da İstanbul Divan-1 Örfi’ye gönderilmesini istemiştir (ATASE Arş, Kl:243, D:16, Fh:84).

Öte yandan Damat Ferit Hükümetleri ulusal harekât karşıtı kişileri de Vali, Mutasarrıf ve Kaymakam olarak atamışlardır. Bu bağlamda, Ertuğrul Livasının bağlı bulunduğu Hüdavendigar (Bursa) Valiliğine Gümülcineli İsmail Bey ve Mustafa Paşa atandı. 13 Mart 1919 tarihinde görevine başlayan İsmail Bey, Milli Mücadele lehinde yapılan tüm faaliyetlere karşı çıktı. Ulusal harekât taraftarı memurları görevlerinden uzaklaştırdı. Örneğin; Bursa Müftüsü Ömer Kamil Efendi'yi görevinden azlettirmiştir. Ayrıca Kuva-yı Milliye yanlılarını, özellikle örgütlenmek maksadıyla faaliyet gösteren subay ve aydınları saptırıyor, bunları çeşitli bahaneler ileri sürerek şehir dışına çıkarıyordu.

İsmail Bey, halkın tepkisi yüzünden 29 Temmuz 1919'da istifa etmek zorunda kaldı. Ancak onun yerine Bursa Valisi olarak tayin edilen Nemrut takma adıyla tanınan Mustafa Paşa, daha sert davranışlarda bulundu, Kuvayı Milliye’ye karşı düşmanca faaliyetlerde bulunur (Erdeha, 1975, s. 333-342).

Diğer taraftan Damat Ferit Paşa'nın Şeyhülislamı Mustafa Sabri Efendi de ulusal harekât taraftarı ve Kuva-yı Milliye için çalışan başta Müftüler olmak üzere din adamlarına baskı yapıyordu. Kimilerini de Kuva-yı Milliye lehinde çalışmaktan vazgeçmedikleri için görevlerinden azletmiştir. Bursa Müftüsü Ömer Kamil Efendi gibi; Denizli Müftüsü Ahmet Hulusi, Sinop Müftüleri Salih ile İbrahim, Isparta Müftüsü Hüseyin Hüsnü, Uşak Müftüsü Ali Rıza, Sivas Müftüsü Abdurrauf, Burhaniye Müftüsü Mehmet ve Antalya Müftüsü Ahmet Hamdi Efendiler de görevlerinden alınmışlardır. Bu arada Mehmet Nuri ile Mustafa Lütfi Efendiler de görevlerinden alınmakla tehdit edilmişlerdir. Ayrıca Ankara Müftüsü Mehmet Rıfat ve Karacabey Müftüsü Mustafa Fehmi Efendilerin de idama mahkûm edilmelerinde Şeyhülislam Mustafa Sabri'nin etkisinin olması kuvvetle muhtemeldir (Sarıkoyuncu, 1994, s. 787-812).

Ayrıca Bilecik ve çevresi Rumları da Müftü Mehmet Nuri Efendi’ye ölüm naralarılya sokaklara dökülmüşlerdir (Sarıkoyuncu, 1992, s. 30). 
Her iki din adamı belirtilen tutum ve davranışlara rağmen, hiç çekinmeden, korkmadan ulusal harekât lehindeki çalışmaları sürdürdüler. İşgallere tepki olarak özellikle İzmir’in işgali üzerine mitingler düzenlediler, ilgili makamlara protesto telgrafları çektiler. İzmir'in işgali üzerine Bilecik'ten Sadaret makamına iki adet protesto telgrafı çekilmiştir.

21 Mayıs 1919 tarihli olan iki telgraftan ilki; "Bütün Bilecik Ahalisi Namına Müftü Mehmet (Nuri)” imzalıdır. Telgrafta; Yunan askerlerinin ve onlara yardımcı olan Rumların işlediği zulüm ve vahşetten duydukları üzüntü dile getirilmiştir (Selvi, 2007, s. 158).

Aynı tarihli olan ikinci telgrafta; "Belediye Reisi Mustafa, Bilecik Ahalisi Namına Müftü Mehmet (Nuri)" imzalıdır. Bu telgrafta da İzmir'in işgali üzerine derhal İtilaf devletleri temsilcilerine protesto telgrafları gönderdiklerini bildirilerek, hükümetten vatanlarının kurtarılması hususunda gereğinin yapılmasını bekledikleri belirtilmektedir (Selvi, 2007, s. 158-159).

21 Mayıs 1919 tarihinde de Sadaret Makamına telgraf çekilmiştir. "Söğüt Redd-i İlhak Heyeti Namına Belediye Reisi Kamil” imzalı telgrafta da işgalden duyulan üzüntü, halkın galeyana geldiği ve İtilaf güçleri temsilcilerine telgraf çektikleri, ancak cevap alamadıkları belirtildikten sonra, köylerden merkeze toplanan ahalinin heyecan içinde hükümetin kararını bekledikleri ifade edilmiştir (Selvi, 2007, s. 160-161).

Öte yandan Müftü Mehmet Nuri Efendi'nin de içerisinde bulunduğu bir heyet Mustafa Kemal Paşa'nın 4 Mart 1920 tarihli bildirisi üzerine; Ali Rıza Paşa Hükümetinin yerinde kalması, bu mümkün olmadığı taktirde Damat Ferit'e yeniden görev verilmemesi, yeni hükümetin "harici düşmanların amaline zahir olanlardan gayri, milletin vusuk ve itimadına layık bir kabinenin teşkili” için Meclis-i Mebusan'a telgraf çekilmiştir (Şahingöz,1996, s.133).

6 Mart 1920 tarihinde Sögüt’ten TBMM’ne, Söğüt Müdafaa-i Hukuk Cemiyeti Namına Heyet-i İdare Reisi Abdullah imzasılya gönderilen telgrafta da özetle şu hususlar ifade edilmiştir:

İtilaf devlerinin memleketimizin geleceği hakkında karar vermekte oldukları şu nazik zamanda; Kanuni Esasi'nin hükümlerine bağll, vatanın kurtuluşunu sağlayacak ve Milli Meclisin güvenini kazanacak tarafsız bir hükümetin iş başına getirilmesi istenmiştir (Şahingöz,1996, s. 191).

Bilindiği üzere Kurtuluş Savaşı esnasında fetvalar savaşına da tanık olunmuştur. Millî Mücadele’nin ilk günlerinde Mehmet Nuri ve Mustafa Lütfi Efendiler gibi pek çok din adamının ulusal harekât yanında yer alması ve Kuva-yı Milliye’yi örgütlemeleri İtilaf güçlerini ve bu güçlerin özellikle İngiliz baskısı altında bulunan Damat Ferit ve hükümetini rahatsız etmiştir (Sarıkoyuncu, 1995, s. 17).

Nitekim Damat Ferit, 5 Nisan 1920'de dördüncü kez sadrazamlığa getirildiğinde ulusal harekât taraftarlarını suçlayan ve bunların öldürülmelerini isteyenler fetvalar çıardı. Bu fetvalardan halk üzerinde en fazla etki sahibi olanı Şeyhülislam Dürrizade Abdullah'ın imzasıyla 11 Nisan 1920 tarihinde yayınlanan oldu.

$\mathrm{Bu}$ fetvalarda özetle ulusal harekât padişaha karşı isyan kabul ediliyor, Kuva-yı Milliyecilerin kötülenerek, padişahın sadık yurttaşlarına zulüm ettikleri gerekçesiyle öldürülmeleri gerektiği ileri sürülüyordu. Çünkü fetvaya göre Millî Mücadele'yi başlatanlar ve bu ulusal harekâtı yönetenler hak-hukuk tanımayan hain, cani, baği, şaki, Hilafet ve Saltanatı yıkmaya teşebbüs eden kişilerdi. Ayrıca, Kuva-yı Milliye’ye karşı savaşırken ölenlerin de şehit olacakları belirtiliyordu (Sarıkoyuncu, 1997, s. 28). 
Dürridzade Abdullah'ın fetvalarının yayınlanmasıyla birlikte başta Düzce, Zile, Yozgat olmak üzere çeşitli yerlerde isyanlar başladı. Bu tehlikeli isyan hareketleri Ankara'nın yakınlarına kadar ulaşmıştı. Millî Mücadele’nin başarısız olması dahi söz konusu idi. Öyle ki, Kuva-yı Milliye ve Millî Mücadele taraftarı askeri birliklerden de firarlar başlamıştı.

Bu üzücü gelişmeler, İstanbul Fetvasına karşı en önemli tedbirin mukabil fetvalar yayınlamak olduğu gerçeğini ortaya koydu. Fetvanın gerekçesi de düşman elinde esir olan Halifeye zorla ve baskı kullanarak ulusal harekatı kötüleyen bir fetva yayınlatıldığı, dolayısıyla geçersiz olduğudur. Bu arada "Makam-ı Hilafet ve Saltanat tahlisi (kurtarılması) lazımdır" hususu da ifade edilmiştir.

Belirtilen gerekçelerle Ankara Müftüsü ve Müdafaa-i Hukuk Cemiyeti Başkanı Mehmet Rıfat Börekçi başkanlığında; Ankara'da bulunan 21 din bilgini bir araya gelerek karşı fetvayı hazırladılar. "Ankara Fetvası" olarak da anılan fetvada; vatanın işgal altında bulunduğu, dolayısıyla vatan savunmasına katılmanın dini bir görev olduğu, bu konuda düşmanla çarpışırken ölenlerin "şehit" kalanların da "gazi" olacağı belirtilmiştir. Ayrıca Ankara ulemasınca hazırlanan fetvada; Şeyhülislam Dürrizade Abdullah'ın fetvalarının başta İngilizler olmak üzere işgal güçlerinin baskısı altında verildiğinden, dinen caiz ve muteber olmadığı da açıkça vurgulanmıştır (Sarıkoyuncu, 1997, s. 34-38).

Öğüt, İrade-i Milliye, Hakimiyet-i Milliye, Açıksöz gibi ulusal harekât yanında yer alan gazetelerde de yayınlanan Ankara Fetvası; 155'i aşkın din bilgini tarafından onaylanmıştır. Bu din bilginleri arasında Bilecik Müftüsü Mehmet Nuri ve Söğüt Müftüsü Mustafa Lütfi Efendiler de vardır ve isimleri ilk sırada yer almıştır. Böylece, Ankara Fetvası, bir tek Dürrizade Abdullah'ın imzasını taşıyan İstanbul Fetvası'nı etkisiz hale getirmiş, milli birlik ve beraberliği pekiştirmiştir. Başka bir ifadeyle, Şeyhülislam'ın hazırladığı fetva, Ankara Müftüsü ve arkadaşlarının fetvası karşısında bir varlık gösterememiştir (Sarıkoyuncu, 1997, s. 25).

\section{İnönü Muharebeleri Esnasındaki Hizmetleri}

Yunanlılar, 15 Mayıs 1919'da İzmir'e ayak bastıktan sonra, Batı Anadolu'daki pek çok yer gibi Bilecik ve Söğüt topraklarını da işgal etmişlerdir. Günümüzde Eskişehir ilimize bağlı bir kaza olan İnönü, Kurtuluş Savaşı esnasında Ertuğrul (Bilecik) Livası- Söğüt kazasının bir nahiye merkezi idi. 6-11 Ocak 1921- 23 Mart- 1 Nisan 1921 tarihleri arasında İnönü ve çevresi topraklarında yapılan çarpışmalar sonucunda Türk Milleti makus talihinin yenmiştir. Bu bakımdan, İnönü Muharebelerinin; Türk Ulusal harekâtı ve Bağımsızlık Savaşı açısından siyasi, askeri ve moral yönünden ayrı bir öneme sahiptir. İnönü Muharebelerinin kazanılmasında; Müftü Mehmet Nuri ve Müftü Mustafa Lütfi Efendilerin de önemli katkıları olmuştur.

Bu iki din adamından Mehmet Nuri Efendi, cami kürsülerinde ve meydanlarda yaptığı vaaz ve konuşmalarıyla mücadele kıvılcımını ateşlemekle yetinmedi. O, başkanı bulunduğu Bilecik Müdafaa-i Hukuk Cemiyeti sorumluluğunda; Kuva-yı Milliye'nin personel, silah, cephane ve malzeme yönünden ikmalinde üstün hizmetlerde bulundu. Ayrıca gönüllülerden Bilecik ve çevresinin asayişini sağlamak üzere kuvvet oluşturdu. Bu kuvvetin büyük bir kısmı İnönü Muharebelerine de katılmıştır. Bu arada bu kuvvetin ikmali de yine Mehmet Nuri Efendi'nin girişim ve gayretleri sonucu sağlanmıştır (Türk Tarih Kurumu Bekir Sami Evrakı, Dosya: 15, Defter: 2, No:303). Öyle ki, "Bilecik halkının mali durumunu yakinen bildiğinden, onlarda güçleri ölçüsünde yardım talebinde bulunduğu, yardım konusunda gönülsüz olanlara Müftülük Makam odasının kapısına yazdırmış olduğu YOK DEMEK YOK ibaresini gösterdiği” günümüzde dahi Bilecik halkınca ifade edilmektedir (Sarkoyuncu, 1992, s. 30). 
Hiç kuşkusuz onun Kuva-yı Milliye’nin ikmali özellikle Bilecik ve çevresinin asayişini sağlaması ve oluşturduğu gönüllü kuvvetlerin; İnönü Muharebeleri esnasında çarpışmalara katılması yönündeki hizmetleri önemlidir. Müftü Mehmet Nuri Efendi’nin Millî Mücadele tarihimiz açısından çok önemli bir hizmeti vardır. Daha önce de ifade edildiği üzere, onun Askeri Polis Teşkilatı emrinde görev almasıdır. İnönü Muharebeleri esnasında düşman kuvvetleri hakkında gizlice elde ettiği stratejik bilgileri, Türk yetkililerine iletmiştir. Onun verdiği bilgilerin, muharebelerin zaferle sonuçlanmasında önemli katkısı olmuştur. Nitekim Yunan kuvvetleri başarısızlıklarını, onun hizmetlerini yorumlamışlardır (Sarıkoyuncu, 1992, s. 32).

Diğer taraftan Mehmet Nuri Efendi, Yunan işgal komutanlarının; “Gelen düşman değil, peygamber askeridir; size hiç zararı dokunmaz” şeklinde camilerde vaaz vermeleri hususundaki isteklerine karşı çıktığı gibi kaza müftülerinin de buna uymamalarını istemiştir (Sarıkoyuncu, 1992, s. 34).

Öteden beri çalışmalarından rahatsızlık duyan Yunan işgal güçleri; onun son hizmetlerini fırsat bilerek pusu kurdular ve yukarıda da belirtildiği gibi 7 Nisan 1921 günü tarassudu sırasında bu yurt sever din adamını şehit ettiler. Çünkü o, çalışmalarına İnönü Zaferi sonrasında da ara vermedi: Yunanlıların Sakarya Savaşı’na yol açan ilerleyişi için mihrak noktası yaptıklarını, faaliyetlerini Türk yetkililerine her an haberdar ediyor ve düşmanın her türlü hareketini adım adım izliyordu. Onun 7 Nisan 1921 günü sabahının erken saatlerinde yasak bölge ilan edilen Eğmedek tepesine çıarak düşman saflarını dürbünle gözetlediğini Bilecik Yerli Rumları, Yunan yetkilerine haber verdiler. O, ülkesi ve milleti için daha çok hizmet edebilecek bir yaşta (36 yaşında) öldürüldü (Sarıkoyuncu, 1993, s. 19).

Müftü Mustafa Lütfü Efendi de kuruluş ve faaliyetlerinde görev aldığg Söğüt Müdafaa-i Hukuk Cemiyeti’nde üstün hizmetlerde bulunmuştur. Genelkurmay Askeri Tarih ve Stratejik Etüt Başkanlığı Arşivinde (ATASE Arş. KL:950, D:2, Fh:74) bulunan deftere göre, oda Sögüt Müdafaa-i Hukuk Cemiyeti, Kuva-yı Milliye'nin ikmalinde bulunmuştur. Bu arada Söğüt merkezi ile nahiyelerinin (Bozhöyük, İnönü ve Mihalgazi) ve köylerinin asayişini sağlamak üzere gönüllülerden kuvvet oluşturmuştur (ATASE Arş. KL:950, D:2, Fh:5$12,13)$.

Ayrıca Söğüt Müdafaa-i Hukuk Cemiyetince yurt savunmasına katılmak üzere "Milli Gündüzbey Taburu", "Savcıbey Müfrezesi”, "Hacı Zafer Efendi Müfrezesi”, "Nafiz Efendi Müfrezesi” ve "Raif Efendi Müfrezesi” gibi kuvvetler teşkil edilmiştir. Bu müfrezelerin hepsi, İnönü Muharebeleri esnasında çarpışmalara katılmıştır (Sarıkoyuncu, 1992, s. 70-76).

Bu kuvvetlerin içerisinde personel açısından en büyüğü Milli Gündüzbey Taburudur. 400 mevcutlu olan bu kuvvet, Müftü Mustafa Lütfi (Kileci) komutasında İnönü Muharebeleri sirasinda üstün yararlılıklar göstermiştir (Sarıkoyuncu, 1993, s. 28).

\section{Sonuç}

30 Ekim 1918'de imzalanan Mondros Ateşkesi sonrası Türk'ün son yurdu Anadolu, emperyalistlerin işgaline uğradı. Öyle ki; İngilizler, Fransızlar, İtalyanlar ve Yunanlılar Şark Meselesini sonuçlandırmak üzere harekete geçtiler. 15 Mayıs 1919'da İzmir’i işgal eden Yunanlılar, tarihler 1921 Ocak ayını gösterdiğinde; Bilecik ve çevresi topraklarına ulaştılar. Özellikle İngilizlerin destek ve yardımını da alan düşman kuvvetleri, Eskişehir üzerinden Ankara’ya yürüyeceklerdi. Böylece Türk Milleti Sevr'i kabul edecekti. 
Ancak emperyalistler umduklarını bulamadılar. Mustafa Kemal Paşa’nın “Milli İntibah” şeklinde ifade ettiği Türk milletindeki uyanış, işgal güçlerini büyük bir bozguna uğratacaktı. "Ya İstiklal Ya Ölüm" parolası üzerine, bütün ulus göreve koşmuş, toprağını, vatanını savunmak için silaha sarılmıştır.

Buna karşın, Millî Mücadele’nin ilk günlerinde halk, Mustafa Kemal Atatürk'ün de ifade ettiğgi gibi gerçeğin farkında değildi. Kimileri de tereddüt içerisinde bulunuyordu. Böyle bir anda pek çok din adamı gibi Mehmet Nuri ve Mustafa Lütfi Efendiler, Bilecik ve çevresi halkının ruhlarında ve benliklerinde var olan bağımsız yaşama azmini ateşlediler. Bu konuda öncelikle camilerde, meydanlarda yaptıkları konuşma ve vaazlarılya halkı aydınlattılar. Ancak onlar, metinde de belirtildiği üzere, mücadele kıvılcımını ateşlemekle yetinmediler. Mitingler düzenlediler, ilgililere işgalleri protesto eden telgraflar çektiler.

Öte yandan ismi geçen din adamları, beldelerini savunmak için halkı örgütlediler. Müdafaa-i Hukuk Cemiyetinin kuruluş ve faaliyetlerinde bulundular. Müftü Mehmet Nuri Efendi, düşman tarafından şehit edildiği 7 Nisan 1921 tarihine kadar Bilecik Müdafaa-i Hukuk Cemiyeti’nin başkanlık görevini yürüttü. Ayrıca her ikisi de Kuva-yı Milliye'nin ikmali konusunda da üstün hizmetlerde bulundular. Müftü Mehmet Nuri Efendi’nin Müftülük makam odasının kapısına "YOK DEMEK YOK” ifadesi, bugün Bilecik halkı tarafından Atasözü gibi söylenmektedir.

Müftü Mehmet Nuri Efendi’nin belirtilen hizmetlerinden başka bir önemli hizmeti daha vardır. Metinde de ifade edildiği gibi Askeri Polis Teşkilatı’nda fahri olarak görev almasıdır. Onun düşman hakkında edindiği bilgilerin, İnönü Muharebelerinin kazanılmasında büyük katkısı olmuştur.

Diğer taraftan Söğüt Müftüsü Mustafa Lütfi Efendi de kuruluş ve faaliyetlerinde bulunduğu Müdafaa-i Hukuk Cemiyeti'nin kararı ile, oluşturulan Gündüzbey Taburunun komutası görevini üstlenmiştir. Metinde de belirtildiği gibi bu müfreze, İnönü Muharebelerine katılmış ve düşmanla vuruşmuştur.

Belirtilen hizmetleriyle Müftü Mehmet Nuri (Kırıkkanat) ve Müftü Mustafa Lütfi (Kileci) Efendiler, Amasya'da Mustafa Kemal Atatürk'ün 24 Eylül 1924 tarihinde yaptı̆̆ konuşmasında Müftü Abdurrahman Kamil Efendi ile birlikte onurlandırdığı din adamlarındandır. Atatürk’ün ifadesiyle, Cumhuriyetimiz onlarla iftihar eder. Bu Cumhuriyetin birer yurttaşı olarak bizler de onlarla iftihar ederiz.

Bu vesileyle, İnönü Muharebelerinin 100'üncü yılında başta İsmet Paşa (İnönü) ile Mehmet Nuri ve Mustafa Lütfi Efendiler olmak üzere bu muharebelerin şehit ve gazilerine öncelikle minnet ve şükran duygularımızı sunariz. 


\section{Kaynakça}

Akçura, Y. (1940). Osmanlı Devleti’nin dağılma devri. İstanbul: Ötüken Yayını.

Askeri Tarih Belgeleri Dergisi, Sayı: 93, Belge No:2399.

ATASE Arş, Kl:243, D:16, Fh:84.

ATASE Arş. KL:950, D:2, Fh:5-12,13.

ATASE Arş., Kl: 687, D: 140, Fh:1-8.

ATASE Arş., Kl:950, D:2, Fh:74.

Atatürk, M. K. (1927). Nutuk. Ankara: İş Bankası Yayını.

Atatürk, M. K. (1989). Atatürk’ün söylev ve demeçleri(Cilt I-II). Ankara: Atatürk Araştırma Merkezi Yayını.

Bayar, C. (1982). Ben de yazdım. İstanbul.

Beğenç, T. (1952). Söğüt. Ankara: Çankaya Matbaası.

Belgelerle Türk Tarihi Dergisi, Sayı:36, Belge No:12.

DİB Arş., D:1923-1212.

Ercan, Y. (1986). Türk-Yunan ilişkilerinde Rum Patrikhanesi'nin rolü. Tarih Boyunca Türk- Yunan İlişkileri (20 Temmuz 1974'e kadar), Üçüncü Askeri Tarih Semineri Bildirileri. Ankara: Genelkurmay Basımevi.

Erdeha, K. (1975). Milli Mücadele'de vilayetler ve valiler. İstanbul: Remzi Kitabevi.

İnan, K. (1986). Türk- Yunan ilişkilerinde dinamikler. Tarih Boyunca Türk-Yunan İlişkileri (10 Temmuz 1974’e kadar), Üçüncü Askeri Tarih Semineri Bildirileri. Ankara: Genelkurmay Basımevi.

İstiklal Madalyası Tarihçesi ve Tanımı, (Tarihsiz). Ankara: Türkiye Muharrip Gaziler Derneği Yayını.

Kocaoğlu, B. (2008). Kurtuluştan kuruluşa Batı Anadolu'da TBMM yardımları. İstanbul: Değişim Yayınları.

Kurat, Y. T. (1973). Batılı kaynakların işığı altında İzmir işgali sorunu. VII. Türk Tarih Kongresi (5-29 Eylül 1970), (Cilt 2). Ankara.

Pehlivanlı, H.(1982). Kurtuluş Savaşı istihbaratında askeri polis teşkilatı. Ankara: Genelkurmay Basımevi.

Sarıkoyuncu, A. (1993). Bilecik ve çevresinde Yunan Mezalimi. Atatürk Araştırma Merkezi Dergisi, 28, 53-71.

Sarıkoyuncu, A. (1992). Şeyh Edebali ve Milli Mücadele'de Bilecik Müftüsü Mehmet Nuri Efendi. Diyanet İlmi Dergi, 30(3), 23-48.

Sarıkoyuncu, A. (1994). Şeyhülislam Mustafa Sabri’nin Milli Mücadele ve Atatürk İnkılapları karşıtı tutum ve davranışları. Atatürk Araştırma Merkezi Dergisi, 13(39), 66-84.

Sarıkoyuncu, A. (1995). Milli Mücadele'de din adamları I. Ankara: Diyanet İşleri Başkanlığı Yayını.

Sarıkoyuncu, A. (1997). Milli Mücadele’de din adamları II. Ankara: Diyanet İşleri Başkanlığı Yayını.

Sarıkoyuncu, A. (2009). Milli Mücadele'de Zonguldak Sancă̆ı: Zonguldak, Bartın, Karabük. Ankara: Zonguldak Valiliği Yayını.

Sarıkoyuncu, A. (2009). Milli Mücadele’de Söğüt ve çevresi. Söğüt: Ertuğrul Gaziyi Anma ve Söğüt Şenlikleri Vakfi Yayını.

Selvi, H. (2007). İşgal ve protesto. İstanbul: Değişim Yayınları.

Şahin, M. S. (1990). Rum ortodoks patrikhanesi. İstanbul: Ötüken Yayınevi. 
Şahingöz, M. (1996). Ali Rıza Paşa hükümetinin istifası ve tepkiler. Ankara.

Tansel, S. (1991). Mondros'tan Mudanya’ya kadar (Cilt I). İstanbul: Milli Eğitim Bakanlığı.

Türk Tarih Kurumu Bekir Sami Evrak1, Dosya: 15, Defter: 2, No:303.

\section{Extended Abstract}

\section{Purpose}

Like many clergymen, Bilecik Mufti Mehmet Nuri (Kırıkkanat) Efendi and Söğüt Mufti Mustafa Lütfi (Kileci) Efendi also took part in the War of Independence. Those who were mentioned in the birth of the idea of struggle and the establishment and activities of the Kuva-yı Milliye had superior services. In addition, Mehmet Nuri Efendi and Mustafa Lütfi Efendi made significant contributions during the "Battles of İnönü", in which the Turkish nation defeated their fortune. The aim of our study is to reveal the importance of their aforementioned services in terms of the War of Independence by making use of archive documents.

\section{Design and Methodology}

Our study is a research article and the design of the study is based on descriptive and causal foundations. Based on the research problem, a framework has been created for data analysis. With this framework, it has been determined that the data will be organized and presented as the activities of Bilecik Mufti Mehmet Nuri (Kırıkkanat) and Söğüt Mufti Mustafa Lütfi (Kileci) Efendes in the War of Independence. During the data collection process, especially the archives of Military History and Studies Presidency and Religious Affairs were used. Documents were classified, data were read and organized according to the thematic framework. After collecting the relevant documents, they were analyzed and the activities of Bilecik Mufti Mehmet Nuri (Kırıkkanat) Efendi and Sögüt Mufti Mustafa Lütfi (Kileci) Efendi in the War of Independence were emphasized. Organized by the definition of the findings, the data were defined systematically. Care was taken to describe the data in an easy, understandable and readable language. With the interpretation of the findings, it was seen that Bilecik Mufti Mehmet Nuri (Kırıkkanat) Efendi and Sögüt Mufti Mustafa Lütfi (Kileci) Efendi took part in the War of Independence, like many clergymen. It was determined that those who were mentioned in the birth of the idea of struggle and the establishment and activities of the Kuva-yı Milliye had superior services.

\section{Findings}

In the early days of the War of Independence, the public was not aware of the truth, as Mustafa Kemal Atatürk had stated. Some were also hesitant. In such a moment, Mehmet Nuri Efendi and Mustafa Lütfi Efendi, like many clergymen, ignited the determination to live independently in the souls and souls of the people of Bilecik and its environs. They enlightened the people with their speeches and sermons in mosques and squares. However, they were not satisfied with igniting the spark of struggle, as stated in the text. They organized rallies, sent telegrams to the relevant people protesting the invasions.

On the other hand, the clergy mentioned above organized the people to defend their land. They carried out the establishment and activities of the Defense of Rights Association. Mufti Mehmet Nuri Efendi served as the president of the Bilecik Defense of Law Society until April 7, 1921, when he was martyred by the enemy. In addition, both of them provided outstanding services in the supply of Kuva-yi Milliye. Today, the people of Bilecik say "don't say we don't have" expression of Mufti Mehmet Nuri Efendi on the door of the office of Mufti as a Proverb. 
Mufti Mehmet Nuri Efendi has another important service besides the mentioned services. As stated in the text, it is an honorary duty in the Military Police Organization. The information he gained about the enemy had a great contribution in winning the Battles of İnönü.

On the other hand, Sögüt Mufti Mustafa Lütfi Efendi assumed the command of the Gündüzbey Battalion, which was formed by the decision of the Defense of Rights Association, in which he was established and engaged. As stated in the text, this detachment participated in the Battles of İnönü and fought with the enemy.

Mufti Mehmet Nuri (Kırıkkanat) Efendi and Mufti Mustafa Lütfi (Kileci) Efendi were among the clergy that Mustafa Kemal Atatürk honored together with Mufti Abdurrahman Kamil Efendi in his speech on September 24, 1924 in Amasya. In the words of Atatürk, our Republic takes pride in them. We, as citizens of this Republic, take pride in them.

\section{Research Limitations}

Previous research forms the basis of the research planned and helps to understand the research problem. However, there are very few studies on our subject. This situation made our work difficult and caused us to focus more on archive documents. In addition, there were problems in accessing libraries and going to archives due to the COVID-19 pandemic. Many resources have been accessed online. Having to ask the institution to deliver the documents by mail both increased the working time and caused not to obtain all the relevant documents.

\section{Implications (Theoretical, Practical and Social)}

It is very important to reveal who the fighters are in the National Struggle in order to keep the national consciousness alive. Mehmet Nuri Efendi and Mustafa Lütfi Efendi also made significant contributions during the "Battles of İnönü", during which the Turkish nation defeated the misfortune of the Turkish nation. It has been determined that the activities of Bilecik Mufti Mehmet Nuri (Kırıkkanat) Efendi and Söğüt Mufti Mustafa Lütfi (Kileci) Efendi in the War of Independence were extremely important in terms of instilling the spirit of fighting in the National Struggle. In this respect, knowing the services of the two heroes of the National Struggle will enable the youth to embrace Republic values more enthusiastically.

\section{Originality/Value}

Unfortunately, the services of Mehmet Nuri Efendi and Mustafa Lütfi Efendi in the War of Independence are unknown. However, they made important contributions to the formation of national consciousness and carried out important duties in the defense of the country, especially by fighting in the Battles of Inönü. In this respect, it is of great importance that the archive documents related to the subject are unearthed and the subject has been processed. In this way, a significant contribution was made to the field by revealing the services and roles of two heroes of the War of Independence, whose names are known only.

Araştırmacı Katkısı: Esra SARIKOYUNCU DEĞERLİ (\%60), Ali SARIKOYUNCU (\%40). 